See discussions, stats, and author profiles for this publication at: https://www.researchgate.net/publication/356014897

\title{
N 2 Oxidation Pathways in a ns-Pulsed Discharge Above Water: O Atoms, No, and Oh Radicals Kinetics
}

Conference Paper · September 2021

DOI: 10.1109//COPS36761.2021.9588569

CITATIONS

0

7 authors, including:

Mikhail V. Gromov

Ghent University

7 PUBLICATIONS 21 CITATIONS

SEE PROFILE

Rony Snyders

Université de Mons

188 PUBLICATIONS 2,985 CITATIONS

SEE PROFILE

Some of the authors of this publication are also working on these related projects:

Project $\quad$ Plasma-based synthesis of nanomaterials View project

Project Novel type of antibacterial coatings on textile materials and plastics with controllable release of antibacterial agent View project
READS

28

Kseniia A. Leonova

Université de Mons

8 PUBLICATIONS 12 CITATIONS

SEE PROFILE

Rino Morent

Ghent University

256 PUBLICATIONS 7,404 CITATIONS

SEE PROFILE 


\title{
$\mathrm{N}_{2}$ OXIDATION PATHWAYS IN A ns-PULSED DISCHARGE ABOVE WATER: O ATOMS, NO, AND OH RADICALS KINETICS
}

\author{
Mikhail Gromov ${ }^{1.2}$, Kseniia Leonova ${ }^{2}$, Nikolay Britun ${ }^{3}$, Rony \\ Snyders $^{2,4}$, Nathalie De Geyter ${ }^{1}$, Rino Morent ${ }^{1}$, and Anton \\ Nikiforov $^{1}$ \\ ${ }^{1}$ Ghent University, Department of Applied Physics, \\ Gent, 9000, Belgium \\ ${ }^{2}$ Mons University, Chimie des Interactions Plasma-Surface \\ (ChIPS), Mons, 7000, Belgium \\ ${ }^{3}$ Nagoya University, Center for Low-temperature Plasma \\ Sciences, Nagoya, Japan \\ ${ }^{4}$ Materia Nova Research Center, 3 Avenue Nicolas Copernic, \\ 7000 Mons, Belgium.
}

Nitrogen fixation (NF) is a process of converting molecular nitrogen into valuable chemicals, such as $\mathrm{NH}_{3}$ or $\mathrm{NO}_{\mathrm{x}}$. These components are used in many industries, in particular as a feedstock for fertilizers in agriculture. Nowadays, industrial NF is associated with high energy consumption and dramatic environmental impact. Plasma-assisted NF can be a good alternative and, with the support of renewable (green) energy sources, it can bring many benefits and reduce the environmental impact of industry [1].

This research focuses on investigating nitrogen oxidation pathways in the presence of a plasma/liquid interface. The atmospheric pressure plasma was driven by $10 \mathrm{~ns}$ long pulses. Temporal-spatial dynamics of the key species were experimentally investigated using laser-induced fluorescence (LIF) and optical emission spectroscopies (OES). The species kinetics were studied varying plasma pulse energy and pulse frequency. A low repetition frequency discharge of $10 \mathrm{~Hz}$ in single pulse mode was compared with a high-frequency burst of $100 \mathrm{kHz}$ to examine if a high pulse repetition rate can improve the plasma-assisted NF.

$\mathrm{O}$ atoms and $\mathrm{NO}$ radicals kinetics revealed that the presence of water creates lingering $\mathrm{NO}$ formation up to $10 \mathrm{~s}$ of microseconds owing to $\mathrm{NO}$ formation in reactions with $\mathrm{OH}$ radicals [2]. The suggested mechanism is confirmed by the measurement of time-resolved 2D profiles of $\mathrm{OH}$ radicals using LIF. Obtained data well agree with previously made suggestions, and together with OES, it gives us a complete picture of the gas-phase chemical dynamics in a ns-pulsed discharge above water. To conclude, this work shows how the presence of water impacts NO formation kinetics, which, in turn, can be used in the optimization of the plasma-assisted NF process.

1. L. R. Winter and J. G. Chen, " $\mathrm{N}_{2}$ Fixation by PlasmaActivated Processes", Joule, 2020, 16p.

2. M. Gromov et al., " $\mathrm{N}_{2}$ oxidation kinetics in a ns-pulsed discharge above a liquid electrode", Plasma Sources Sci. Technol, 2021, 14p.

\footnotetext{
* Work supported by the Excellence of Science FWO-FNRS project NITROPLASM (EOS ID 30505023)
} 